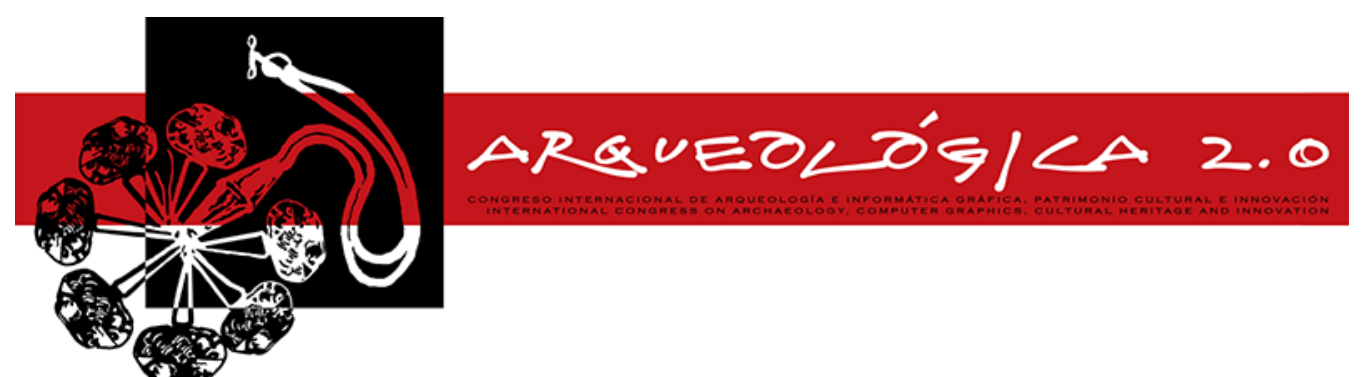

Proceedings of the $8^{\text {th }}$ International Congress

on Archaeology,

Computer Graphics,

Cultural Heritage and Innovation

'AROUEOLÓGICA 2.0'

in Valencia (Spain),

Sept. 5-7, 2016

DOI: http://dx.doi.org/10.4995/arqueologica8.2016.3318

\title{
PHOTOGRAMMETRIC SURVEY AND 3D MODELING OF THE FUNERARY URN DEPICTING THE MYTH OF OENOMAUS, FOUND INSIDE THE TOMB OF THE ETRUSCAN FAMILY OF CACNI IN PERUGIA (III-I CENTURY BC)
}

\author{
LEVANTAMIENTO FOTOGRAMÉTRICO Y MODELADO 3D DE LA URNA FUNERARIA QUE REPRESENTA EL \\ MITO DE ENOMAO, ENCONTRADA EN LA TUMBA DE LA FAMILIA DE LOS ETRUSCOS CACTOS EN PERUGIA \\ (III-I AC) \\ Daniele Calisi
}

Dipartimento di Architettura, Università degli studi G. D’Annunzio Chieti Pescara, Viale Pindaro, 65127 Pescara, Italy. d.calisi@gmail.com

\begin{abstract}
:
The urn, recovered in 2013 by the Cultural Heritage's Police Command along with other 21 and with the funeral set of the tomb of the Cacni family at Perugia, was exhibited at the Quirinale and then moved to Perugia, at the National Archaeological Museum of Umbria. 2014. After a first attempt to survey the laser scanner, the survey, aimed at the graphic documentation and implementation of a virtual model for the study and dissemination, has been performed with photographic processed with software modeling structure from motion.

3D model in mesh made with the appropriate software has been cleaned of all its impurities: holes, tips, noise and rough surfaces. To conclude the process, the mapping from photography, with high resolution textures, giving the mesh the appearance next to the real funerary urn. The survey work on the urn of Oenomaus is a case in point, both for research of best practices in the surveys of archaeological objects, both in the ultimate goal of the relief: not only cataloging and knowledge, but also of divulging to a wider public.
\end{abstract}

Key words: virtual archaeology, digital archaeology, 3D reconstruction, etruscan funerary art, photogrammetry, photomodelling, texturing, Mesh managing

\section{Resumen:}

La urna, recuperada en 2013 por el Comando de Policía del patrimonio cultural, junto con otros 21 y con el conjunto funerario de la tumba de la familia Cacni en Perugia, fue exhibida en el Quirinale y luego se trasladó a Perugia, en el Museo Arqueológico Nacional de Umbría. 2014. Después de un primer intento de estudiar el escáner láser, el levantamiento, dirigido a la documentación gráfica e implementación de un modelo virtual para el estudio y la difusión, se ha realizado con procesado fotográfico con software de modelado structure for motion.

La malla 3D realizada con el software adecuado se ha limpiado de todas sus impurezas: agujeros, las extremidades, el ruido y superficies rugosas. Para finalizar el proceso, el mapeo de la fotografía, con texturas de alta resolución, dando la malla la apariencia de la urna funeraria real. El trabajo de investigación en la urna de Enomao es un ejemplo emblemático, tanto para la investigación de las mejores prácticas en levantamiento de objetos arqueológicos, tanto en el objetivo final del relieve: no sólo la catalogación y el conocimiento, sino también el difundir a un público más amplio.

Palabras clave: arqueología virtual, arqueología digital, reconstrucción 3D, arte funerario etrusco, fotogrametría, fotomodelado, texturizado, malla de gestión

\section{Introduction and study cases}

In recent years the use of laser scanners and photographic modeling has increased significantly. They are now essential tools especially in the surveying and knowledge of the built. However, it is the archeology sector that lately is mainly using these tools. Particularly in the excavations, it is essential to document and save the data of each stratification: no instrument can be today more useful to for scanning the layer of which we have to build the digital surface. No more photographs to witness the excavation but three-dimensional models "layered". Personally, I experienced both technologies and practice allows us to understand and analyze the methodologies that become experimentation and then sap for research in the field. 
One of the first work performed with the software PhotoScan, was an assignment for the survey and photogrammetric survey of the Lodge of the Rector's Palace in Dubrovnik designed by Onofrio della Cava. Photografic campaign aimed at creating a 3D mesh model with software structure for motion of the engraved capitals by Pietro di Martino da Milano.

We performed a $3 \mathrm{D}$ modeling, high resolution texturing and profiling of the capitals of the porch (consultancy related to the Recovery Plan of the urban space promoted by the Municipality of Ragusa. 2013/2014).

Among the capitals finely chiseled, one in particular has special prestige for the shapes and the executive detail. The point cloud and 3D mesh model were realized through a detailed photographic campaign (Calisi 2014). The distance of the mesh points is less, in some cases, than $1 \mathrm{~mm}$, ensuring a very faithful reproduction of the original. In addition, the high-resolution texture allows also to better appreciate the 3D display.

A second case study, following the Croatian experience, is in Rome: the church of Santa Maria di Loreto in the Forum of Trajan. An entire building, no longer a portion of it. In this case, the data provided by the photographic restitution are less detailed, because it is obviously less close up the photographic campaign. Having to frame the entire building is at the expense of details capitals or moldings. However, the analysis of the point cloud and mesh model, the comparison with the original design or with later surveys, have provided interesting and innovative conclusions on the seventeenth-century church (Calisi and Cianci 2014).

The use of photographic modeling in this case study is one consistent for the reconstruction of the basement floor, attributed to Antonio da Sangallo, the verification of the measures and proportions and the search for the basic module, however measured in palms (Fig. 1).

I leave to the reader the desire to better understand the topic by reading the article inserted in the bibliography.

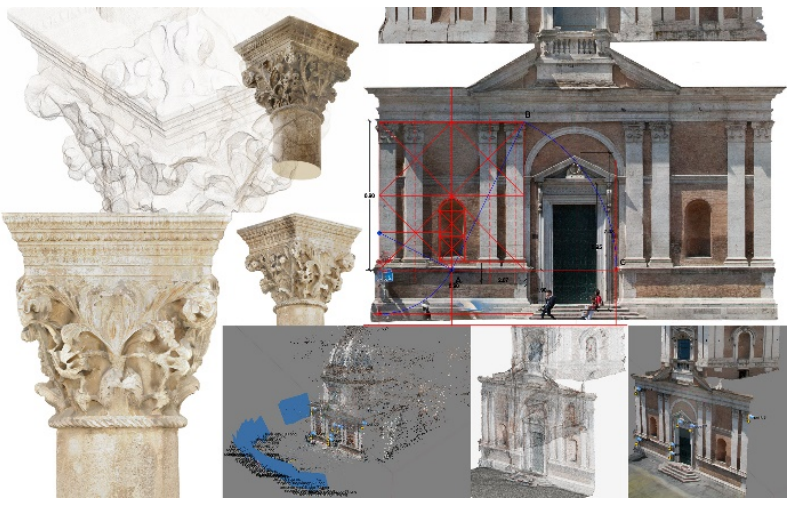

Figure 1: Two case of study: the capital Lodge of the Rector's Palace in Dubrovnik; Santa Maria di Loreto in Rome. 3D

modeling, high resolution texturing. Analysis and comparison of data.

For this paper, however, I present another job followed with Margherita Caputo and Luisa Bogliolo, which is inherent to the archeology theme, it is a wonderful Etruscan urn. In the last months of 2013, the engineers of the Central Institute of Restoration were engaged in the restoration of 21 Etruscan urns and a lid sarcophagus and their kit, retrieved by the Police after a long detective investigation (Godart 2014).

The choice of the urn to detect fell on the one depicting the myth of Oenomaus, dated between the late third and early second century $\mathrm{BC}$, for different reasons: a) the plasticity of the high relief; b) the narrative succession masterfully recounted; c) the richness and detail of the figures and decorative elements; d) the rests of gilding surface that emphasize the narrative elements of the composition; e) the traces of blue that highlight the bottom part while the red color defines the hairstyles.

An urn that has a unique artistic importance. Moreover, all the elements described provided the opportunity to make a virtual model for the study and dissemination, as well as the production of orthophotos and 2D graphics for documentation of techniques of execution, of the conservation status and restoration interventions.

On the basis of the objectives pursued it was decided to perform a three-dimensional survay of precision, enabling a high-resolution digital modeling that can also be used for the possible reproduction of the object as well as for the more traditional 2D drawings (Fig. 2).

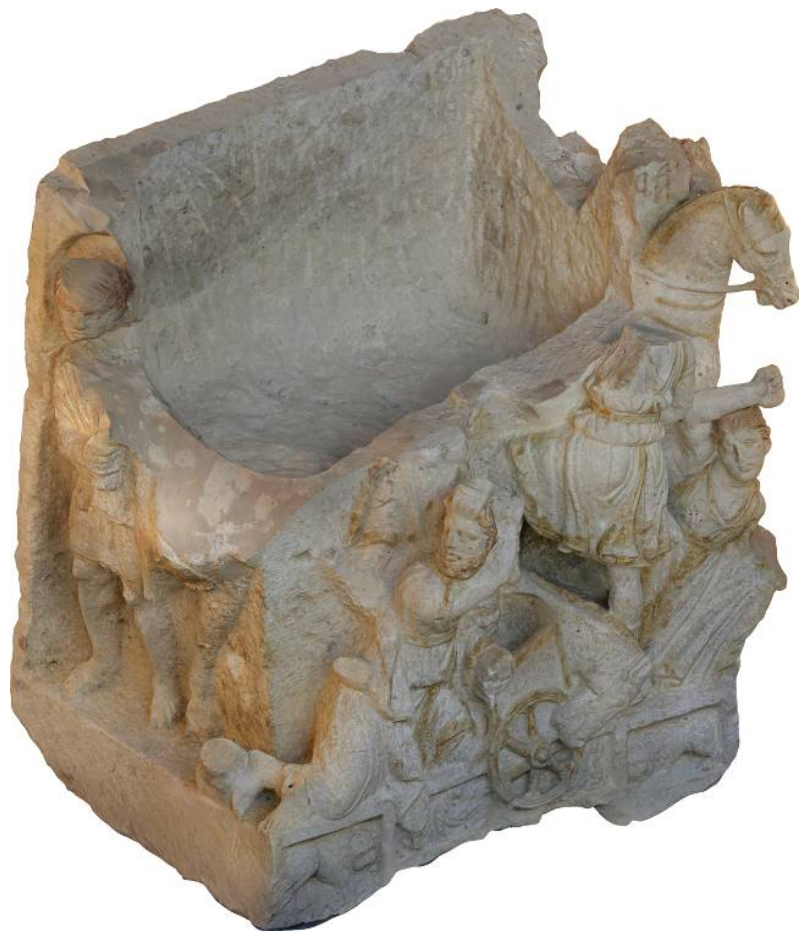

Figure 2: Orthophoto in isometric view (parallel projection), made by PhotoScan. the 3D model is mapped directly from the photos with textures of 16,000 pixels per side. Two of the three sculpted sides are shown.

The choice of technology to be used has been affected by both the instrumentation used both by time, limited, for the acquisition and data processing. We had the availability of a laser scanner Leica HDS 6200 phase shift detection, useful for application to architectural scale, but little effective for close-ups and for the appreciation of details below $1 \mathrm{~mm}$.

But finally, it was decided to experiment with digital photogrammetry that, starting from a set of twodimensional images and making use of algorithms SFM (Structure from Motion) complemented by stereo 
matching algorithms that allows to obtain photo-realistic 3D models that contain all the information (geometry and texture) quickly with use of hardware and software solutions low cost or open source and without renouncing to accuracy and quality of the result.

According to the camera that is used is also possible to determine the scale of representation in which it is possible to show the detected object, so that details are not lost. To calculate it takes advantage of the GSD, ground sample distance, which identifies the smallest element of real space that can be represented in the digital image, taking into account the sensor pixel size.

It is obviously useful when the survey design, to determine the distances of the shooting points from the object. However it is just as useful, if you were bound to cramped conditions or impossibility, instead, the closeups, to understand to what scale of representation you can push in the final communication.

The proportional relationship between the shooting characteristics are:

Focal Lenght: Pixel size of the sensor $=$ Distance camera object: GSD

The focal lenght is determined by the distance of the sensor from the projection center. The size of the pixels of the sensor is a given by the DigiCams factory. The unknowns at this point, in this equation, can be or the shooting distance, or the GSD, that is the minimum recordable detail.

In the case study, instead, the GSD is the equation's unknown: because of the reduced physical space, all shooting was done at an average distance of about 2 meters, with a EOS 5D Camera, with a pixel size of $2 \mu \mathrm{m}$, with a $24 \mathrm{~mm}$ focal length. Then:

GSD $=(D \times$ pixel $) / f$

GSD $=(2000 \times 0,0082) / 24$ (all in $\mathrm{mm})$

GSD is $0,683 \mathrm{~mm}$, which means that from this distance it is possible to represent less than one millimeter without having representation errors. Which of course it makes me realize that the detail of the 3D model that I will get will have a very high resolution, with a consequent heaviness of the file, and management difficulties.

However, the team has preferred to work, during shooting, ensuring the highest possible resolution, also in view of possible future technological developments and provide for the decimation of the mesh in the second phase, preserving in a separate file the original mesh.

The relief has always been a necessary tool for the analysis and knowledge of an object, but in recent years it is possible to perform surveys with a high level of detail thanks, in particular, to the use of photogrammetry systems based on images processed by algorithms of automation of Computer Vision. The results that can be achieved with these new technological applications are of great interest especially in the fields of application of the Architectural and Archaeological Heritage.

In photogrammetry, the techniques used for orientation, as the collinearity equations, ensured greater accuracy. However, the ever-greater accuracy in Computer Vision and reliability of the result have called, in a sense, in the discussion the rules of photogrammetric. In the image based modeling shall apply different algorithms and linear mathematical models for calculating the orientation and searching of the homologous points, in a more simple but at the same time more efficient way.

One of the expedients which allows a better calibration of the orientation of the camera is definitely to have a major characterization of the surfaces of the objects to be detected: a uniform and white stone hardly lead to the realization of a three-dimensional model, but it doesn't happens for the urn of Oenomaus, where we find a porous travertine (with holes of different sizes), painted in different areas and in which there are also evident light and shadow zones.

\section{Analysis of photogrammetric survay}

The funerary urn of Oenomaus was likely to be placed against a wall, or with one side not visible. However, the particular archaeological discovery, isolated from the context, gives great importance to each his portion: for this reason it was decided to proceed with a photo campaign aimed to the survey and the creation of a three-dimensional model that embraced each side of the urn, except for the basement of support.

Five out of six sides therefore have been the subject of a photographic campaign that would allow to shoot the work in its entirety.

It is possible to recover the spatial coordinates of a point, using the rules of photogrammetry, using at least a pair of photographs from two different points of view, in which, of course, the point of unknown coordinates is visible. The two frames are placed in relative position but such as to respect the position of the shoot (exploiting some intrinsic parameters of the camera and extrinsic ones of the environment) (De Luca 2011).

For each real point $\mathrm{P}$ there are two homologous points $\mathrm{P} 1$ and $\mathrm{P} 2$ on the respective frames and for each one there is a visual ray which start from the relative point of view, intercept the homologous points and should intersect in space in one and only one point (P) (Fig. 3).

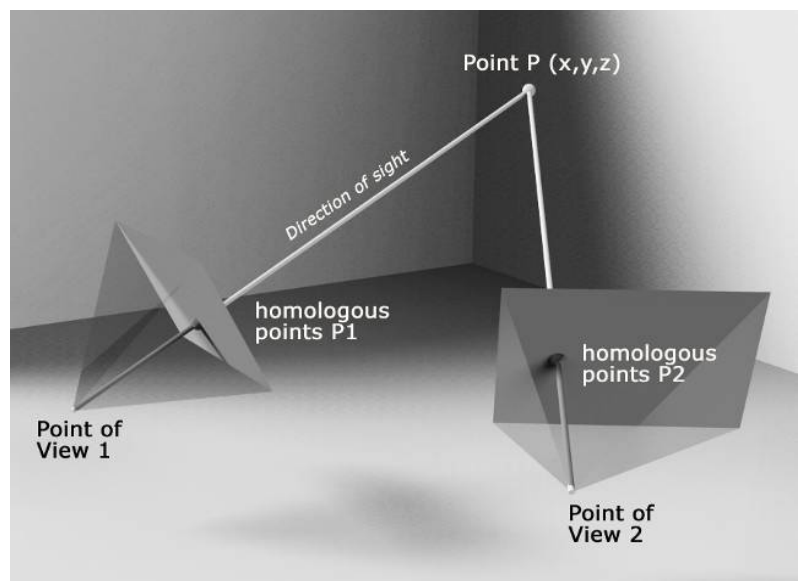

Figure 3: Scheme of reconstruction of the ordinates of a point $\mathrm{P}$, given two photographs randomly oriented in space and sighting the same point.

The 3D image is defined as a set of points in space, a cloud of points, corresponding to the respective homologues in the photos, from which we can start for 
the realization of a real three-dimensional model in mesh (De Luca et al. 2011).

Some modern software, such as Agisoft Photoscan, allows creating mesh models that can be scaled, in which set some points called target, and on which take any measures that are needed, without having to perform a direct survey.

However, the realization of the $3 \mathrm{D}$ model is a complex process and requires good knowledge of shooting and photographic technique, and knowledge of the software used.

In our case, the camera was placed in about one hundred and forty different positions, following meridians and parallels of an ideal sphere that envelopes the urn itself.

Even the orientation of the camera changed by position, basically following the normal to the sphere at the point of station: in a central location we sight the equator; in a lower position looks upward and vice versa for the upper position (Fig. 4).

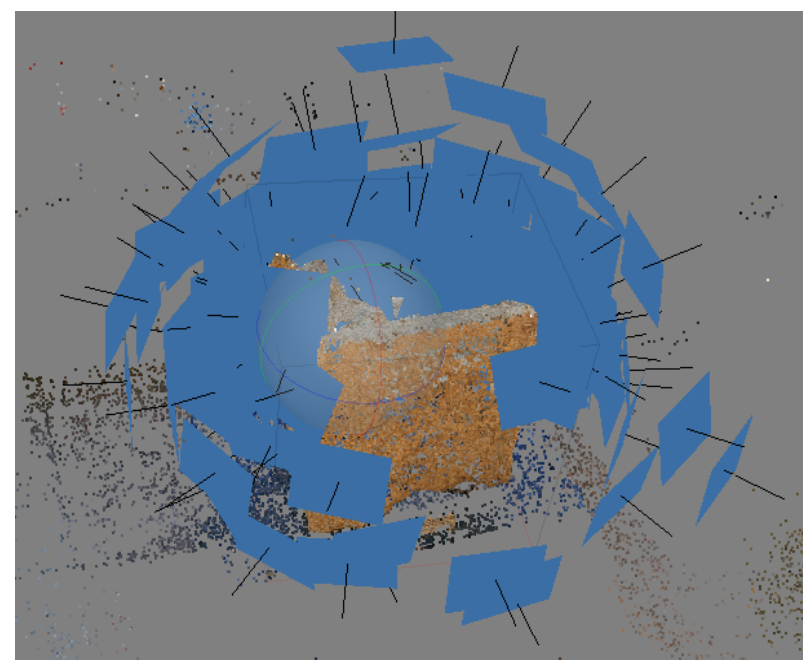

Figure 4: Alignment of the 138 positions of the camera, from which we photographed the urn, according to a virtual sphere divided into meridians and parallels.

The density of shooting has allowed to cover virtually with photos every portion of the urn, which is essential for the posthumous realization of a high-resolution textures.

Moreover the pictures are at full resolution of the camera and, considering the need to have perfectly clear shoots, was used a Canon EOS $5 \mathrm{D}$ with $24 \mathrm{~mm}$ lens, a diaphragm rather closed (the large windows in front of the urn provided enough light) to $f$ / 16 which would widen the depth of field and have each point of the urn in focus within the photograph.

This is in reality a necessary condition for the success of the three-dimensional reconstruction: in fact, if the software identifies the orientation of the cameras even through the matching of homologous points recognized in two or more frames, it is evident that the more the image will be in focus the more precise will be the calibration.
Recognition of points inside of the pictures is essential and it is necessary to use all the tricks to be able to get the highest possible number of pairs.

For this purpose, the areas not reached by direct light of the window were illuminated using auxiliary lights, artificial and with rather large diffusers to simulate an area light, completely analogous to that of the main glass window.

The use of artificial lights that blend with the natural light, however, causes chromatic effects less than optimal: the urn appears to be in part under cold temperature color of lighting and partly under a different color temperature, of a warmer tone. The particular location and reduced space does not, unfortunately, have allowed a similar type of homogenous illumination all around the urn: the window was being totally binding from this point of view.

However, despite being a negative factor from the purely chromatic point of view, this anomaly has also allowed a more accurate recognition of the positions of the cameras.

In fact, thanks to the colder colors areas due to natural light and to those warmer due to artificial light, the software has organized better the spherical grid that envelope the model, and the recognized better the orientation of the camera.

The color problem was solved in the next step, after the positive result in the creation of three-dimensional model (Fig. 5).

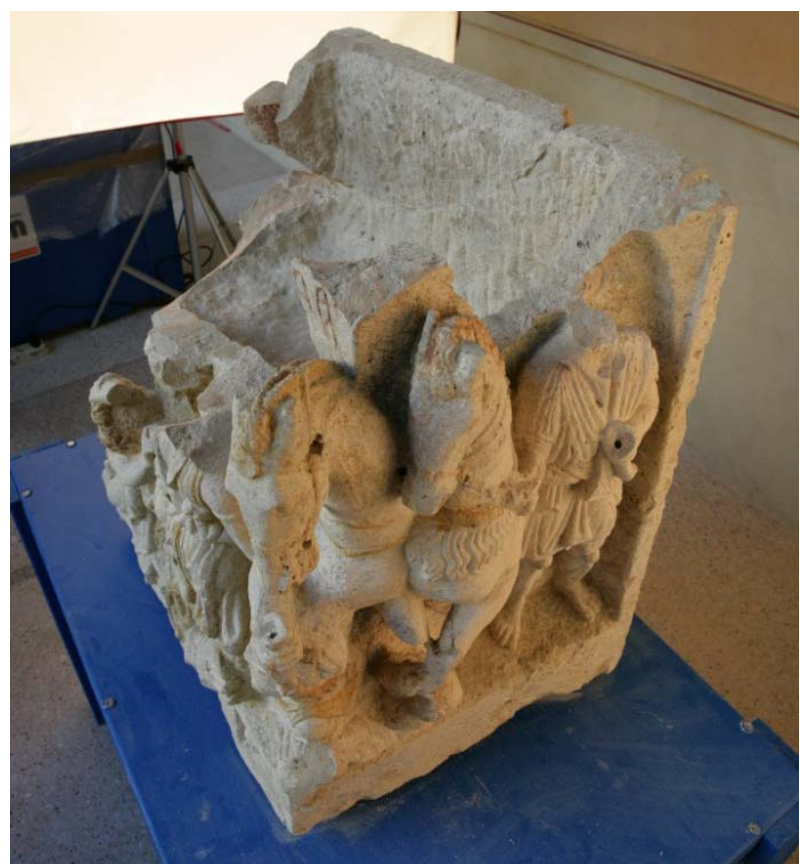

Figure 5: The funerary urn of Oenomaus, placed over a large wooden base, and artificially lit for backs. The mixture of natural and artificial light, has caused some color effects useful to the recognition of homologous points: the main front is subjected to natural light with cold tone; the two side faces are exposed to cold tones and warm tones (caused by artificial lighting); the back face has only warm tones because it is almost completely illuminated by artificial lights. 


\section{Analysis of the mesh obtained: problems of open holes and heaviness of the file}

The software used for the construction of the model was Agisoft PhotoScan. The algorithm used is that at the basis of normal photogrammetry: recognition (no more manual but systematic) of corresponding points (homologous) in at least two shots, identification of the points of view on the basis of internal parameters of the cameras, and finally tracking of two visual rays which depart from the point of view, pass through the homologous points and intersect in space recreating the original spatial coordinates. This process is, however, carried out not more for only two frames, but for a much larger amount (138 in this case).

The first step therefore is to align all the photographs taken. In this phase, the software examines only some homologous points to create a grid, a point cloud discreet and lightened. In this case, for example, of approximately three hundred and eighteen thousand points, which are obviously a considerable amount, that is to envisage a three-dimensional mesh model very detailed. The internal parameters of the camera are essential for the recognition of spatial positions: focal length, orientation, features of the body of the camera and the targets used, are stored in the metafile of every shot.

The parameters for the alignment of the camera in PhotoScan have been set to the maximum. Very high accuracy, because in this way there is greater accuracy and the software works with full-size images. Lowering this value we downscale image size to a quarter (half each side) and subsequently of $1 / 16$. Pair preselection is set to Generic preselection mode: in this way the overlapping pairs of photos are selected by matching photos using lower accuracy setting first (Fig. 6).

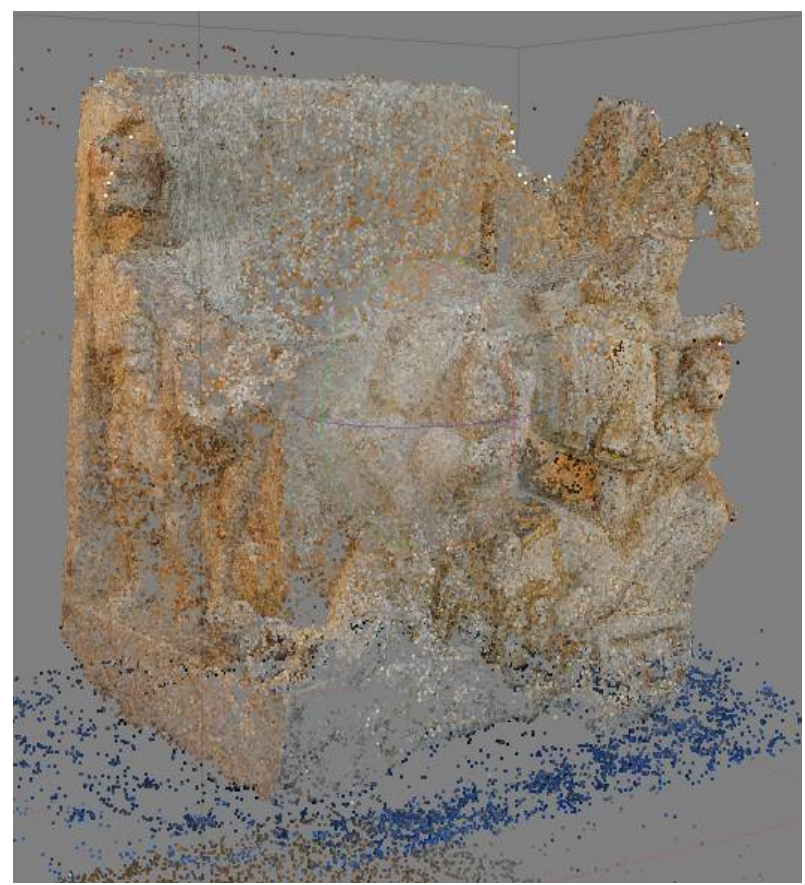

Figure 6: Synthetic cloud of homologous points generated by the software following the first alignment of the positions of the camera.
The second step involves an increase of detail through the recognition of many more points within the grid of characteristic homologous points of the beginning. Than create the geometry, ie the mesh, in triangular surfaces (sometimes square, quad) whose vertices has placed on points of the dense cloud.

The parameters set for the creation of the geometry primarily concern the type of object, which in this case is arbitrary, that is, a generic object and amorphous rather than planar as a ground. The geometry is set to sharp, to avoid that the software would combine arbitrarily holes that are inevitably create. Quality target was set at medium in definitiva.purtroppo a high value not allowed to get a result because of PC crash.

The density of the points is sometimes really impressive: in the case proposed vertices are about ten and a half million, with a distance between the points, at times, of less than a millimeter.

A mesh that is so dense unfortunately, at least with normal hardware instrumentation, is even impossible to navigate. Each operation on the mesh is inevitably fatal to the stability of the processes of the PC, so as to lock the system constantly.

Unfortunately this is a common problem now with modern instruments: increasing amounts of information (captured with a laser scanner or through photomodeling) have no equivalent and constant development of hardware.

Even also by an analysis of the obtained mesh (requireing more work in post processing), that is dense but with dirty areas or holes in the surface, we felt it was necessary and inevitable to provide for a gradual decimation of mesh. This is a simplification by elimination of triangles, trying to find an appropriate solution between the density made to the model by the software and the manageability of the same with the appropriate software.

The decimation made was rather significant, from twenty million faces to five million faces. However, this strong decimation did not alter the formal characteristics of the digital urn and with the creation of a high resolution textures applied to the mesh seems almost that there are no differences in definition.

Moreover, as already mentioned, the surface presented of open holes, voids, essentially caused by two reasons: a problem of shooting, and a poor lighting in much hidden areas. The first reason is depended on local conditions: the urn placed on a large wooden base that however hid shots that should have made from the ground, aiming upwards. Therefore, some areas were not fully covered by the photographs, especially the lower portions of protrusions in the low end of the urn. The second reason, instead, it depends on the inability of the software to recognize homologous points in dark areas, where there is a strong contrast. Therefore, in those areas, the algorithm is not able to complete the surfaces.

Agisoft PhotoScan is not a program dedicated to the management of the mesh, therefore in order to refine the obtained model we had to export in OBJ format to be able to manage with other platforms like MeshLab, or, in our case, with Geomagic (Fig. 7 -8). 


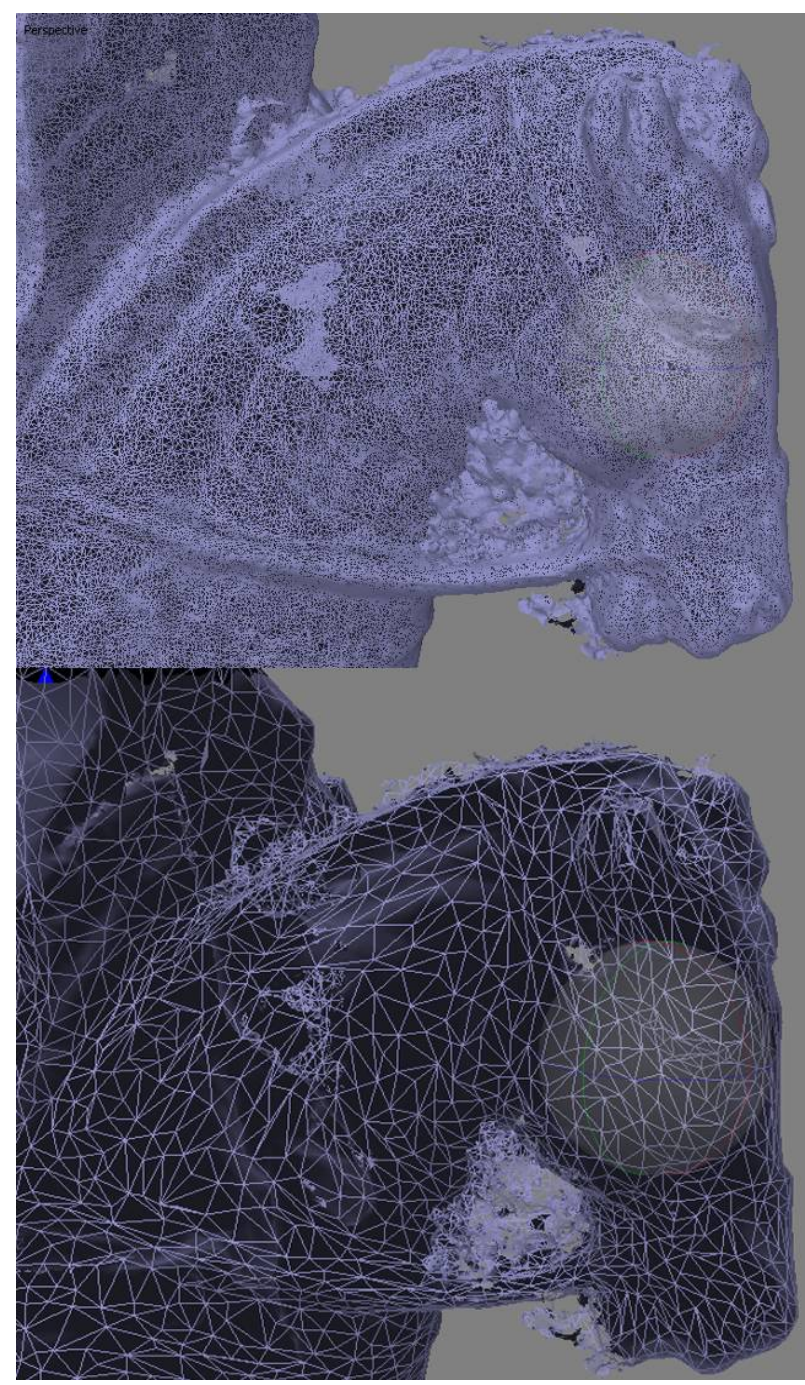

Figure 7: Decimation of the mesh: loss of detail, but the shape is consistent with the original. Unfortunately, the inability to manage the model mesh ten and a half million vertices, led us to having to make such extreme decimation. The mesh obtained, seven hundred thousand vertices, is definitely less detailed, but manageable. The high-resolution textures, however, will compensate the loss of detail in the model.

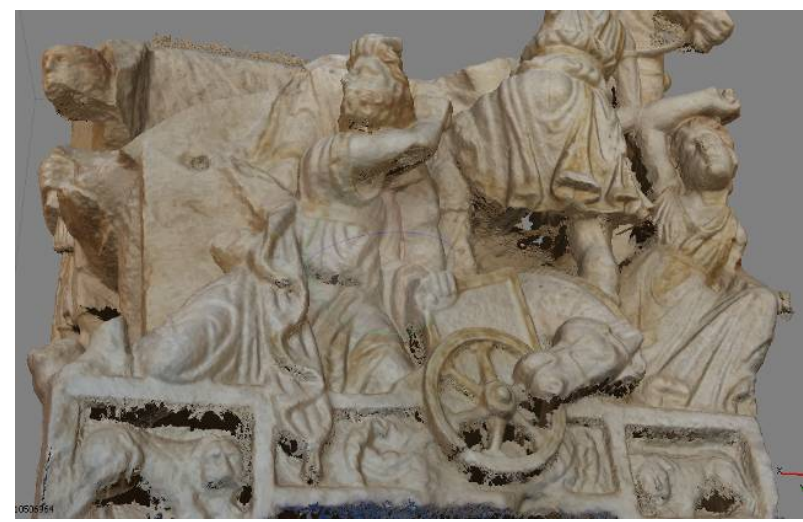

Figure 8: The model presents dirtying and holes especially in the lower parts respect to protrusions.

\section{Open or dirty mesh: closing the holes and cleaning the mesh}

Cleaning the dirty mesh is fundamental and needs the right tools to be able to get a good result: Geomegic allows a wide range of solutions to problems.

First, the cleaning of all those small portions of the mesh "shredded", that is, at corners where the separation between the object to be modeled and the background is not clear. In these areas are always present small portions of mesh partially connected with the mother mesh because of errors of assessment. These areas must be removed automatically (they can be highlighted with a gradual selection and then deleted all together if they are detached from the mesh) or manually (one by one, making sure, then, to close the holes created).

In other areas it is possible that, although there are no particular outgrowths, the mesh is still very rough and crude so much that needs to be polished with the necessary tools, to eliminate spikes and noise (rounding the sharp corners), or repair the normal to the surface. The mesh can also be carved as if it were a real piece of clay.

Furthermore, closing of the holes of the mesh are difficult operations to perform. For some holes, it is possible to perform an automatic closing simply by setting the type of curvature to be used for the patches to be applied, but in other cases, where the hole is more extended, the reconstruction must be reasoned.

Often it must proceed to subsequent steps. First recreating some bridges between the meshes, which also have a certain curvature and take account of the tangents to the extreme edges of mesh triangles: in this way, the bridge will be tangent to the existing surface and will have a greater or lesser curvature, set by the user and consistent with the reconstruction.

When the holes are too large and are of very inhomogeneous areas, the software is not able to reconstruct the mesh in the hole because is not able to exploit the tangent to the surface of each mesh edge of the hole. It is therefore necessary to manually creating more bridges in sequence and finally close the holes. In some cases, it is also necessary to clean the hole itself, eliminating ragged mesh, prominent tips, or malformations of the surface: the aim is to get a clean hole with smooth edges.

The closing of the holes is finally also, as for bridges, regulated by a curvature at the discretion of the user: if we are in flat surfaces can also be setted at zero, otherwise we could increase the camber. However, in most cases it is appropriate to leave the curvature not setted. In fact, this does not correspond to achieve flat surfaces, but to avoid interpretations: the software always takes into account the tangents to the edges of the hole, and create an area to cover the hole that interpolates all tangents without adding additional curvatures (Fig. 9). 

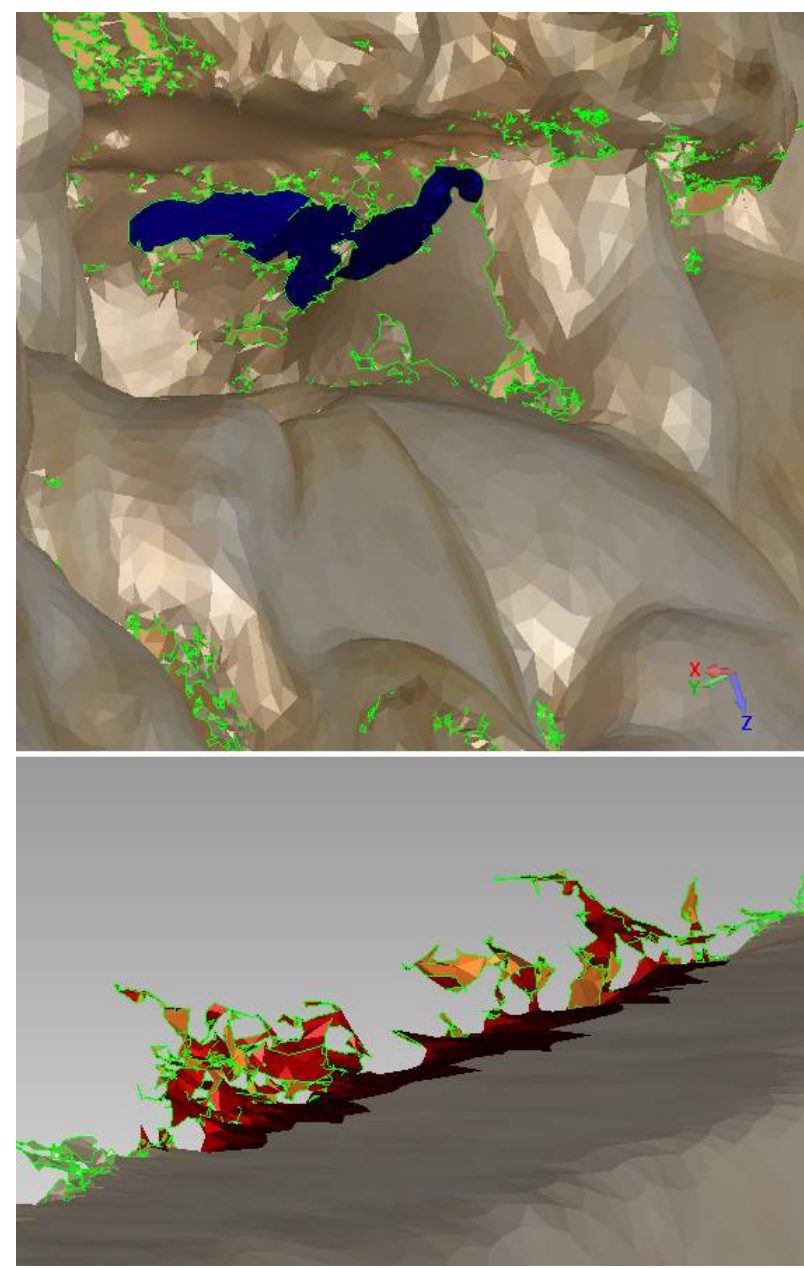

Figure 9: Cleaning of the mesh. In order to close the holes very large, it is necessary to build bridges at variable curvature which link very distant parts of the mesh. In some cases, instead, it is necessary to clean the ragged surfaces at the edges of the mesh.

\section{Mesh processing and photographic postproduction}

The cleaning of the mesh is certainly very accurate in Geomegic and the underlying result is very good and accurate. However, we must be careful not to move the model in the digital space to avoid problems in the next phase of re-importing into PhotoScan: the closed and corrected mesh, in fact, can be reported in the source software, taking the same position as the original. Nevertheless, we have to avoid problems of slipping of anchor with the original locations of the cameras which had created the first 3D mesh model.

This step is in fact necessary in order to achieve, in the last phase of the process, the high-resolution textures, to apply to the mesh, which is created starting precisely from original photographs through a rather complex process.

The algorithm used provides for the View-Dependent Texture Mapping, which is a kind of mapping of the mesh that affords for the calculation of the normal to the surface and mapping from partial picture: it extrapolate from the pic only the portions that are as parallel as possible to the mesh destination.
The procedure performed for all the photos of the model. Therefore, to create a texture composed of the hundred and thirty-eight pictures in which every part is very sharp with no aberration.

Therefore, in a zone of strong curvature software will map the mesh using each time those portions of photographs that will become more parallel to the surface at a given point.

The user can choose the resolution of the texture also depending on final use: VRML for Web, textured orthophoto, exporting the model with mesh texture for film postproduction and so on.

However, as already described at the beginning, in the case study there was a problem of lack of homogeneity of the light, and some photographs were tacking toward cool tones, while other ones to warm tones.

Therefore, we considered to make the correction of the images in postproduction, before the implementation of the final texture. So that, for proceeding efficiently to the replacement of the images, however, we must applied a trick: do not change the folder source nor the names of files, otherwise we could lose the alignment of the cameras, but also the geometry created and re-imported in Photoscan.

It is therefore good practice to copy the originals in a subfolder before proceeding to their modification. At this point, we could keep on to postproduction and saving the file to overwrite.

The color balance of the photo was made with Adobe Lightroom, a digital darkroom. We imposed to the images a white balance set manually (with the eyedropper tool) on some white sheets placed on the wood basement: imposing what were the white absolute point and the software initiates the color change of the whole picture as a function of it.

In this way, we eliminated the hot component in the images artificially lit, and the component too cold in the images in which the natural light is greater. A uniform set of images was such performed (Fig. 10).

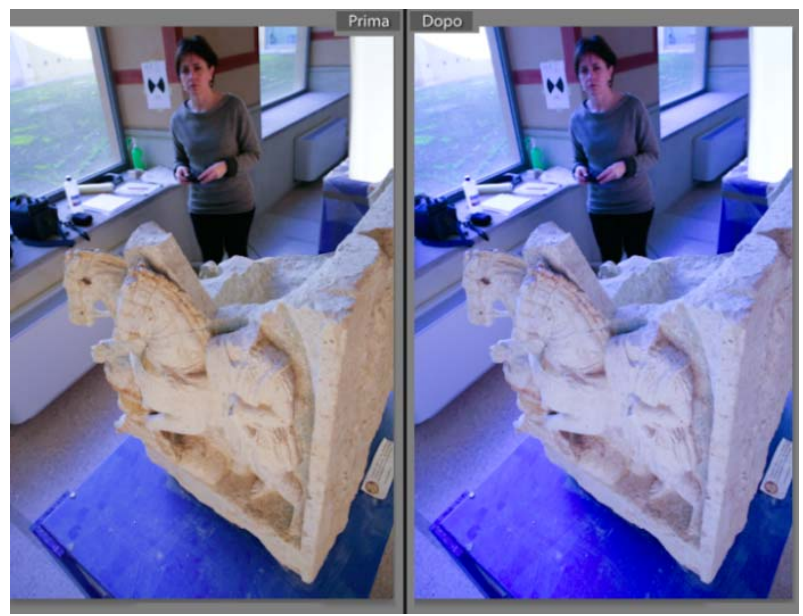

Figure 10: White balance in post production. All pictures (lighted with daylight or artificial light) were tacking, imposing the absolute white point by some paper sheets over the wood basement. In this way it was possible to standardize the photo set to obtain a more realistic texture. 
The software will recognize the changes saved to the original images, but without going to affect the mesh model, and then it will be possible to start the realization of a high-resolution mesh, 16.000 pixels (each side), that will wrap the closed mesh (Fig. 11).
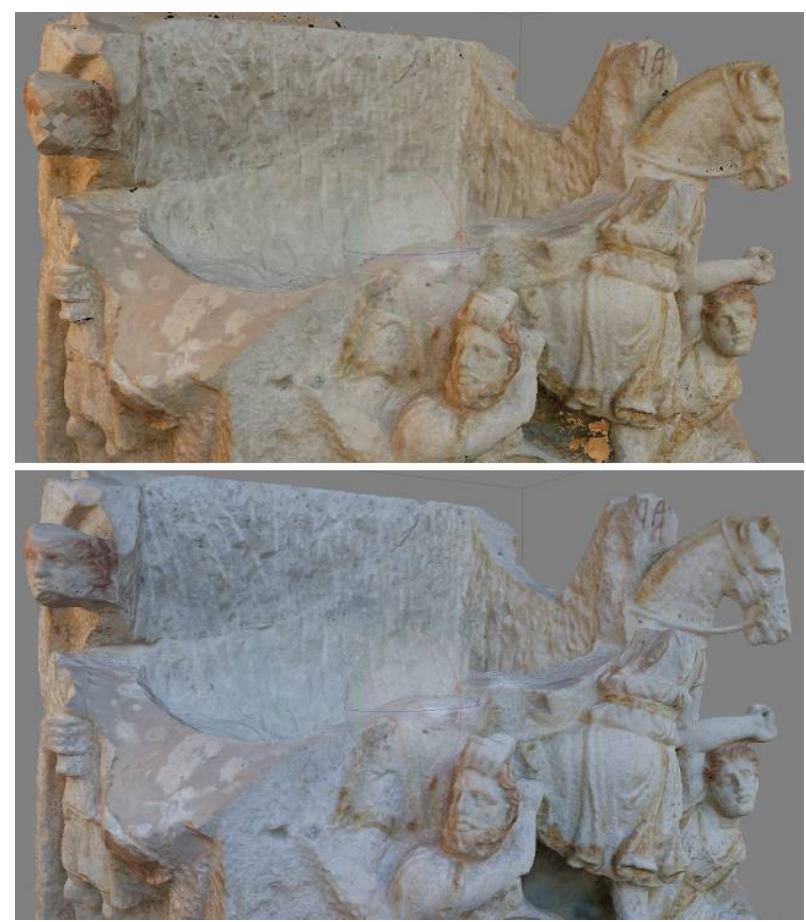

Figure 11: The mesh model without texture in comparison with the clean model, imported back into PhotoScan, and textured with toned pictures.

The softwares allow the direct creation of orthophotos from the 3D model, that is, high-resolution views in orthogonal or isometric depending on the projection plane and the point of view considered (Pierrot Deseilligny et al. 2011).

In this way, we can create accurate and faithful elevations of the object that would not have been possible to create with the original Etruscan.

To do that it need to fix the target points, characteristic points selected in the photos, which allow us to impose the $\mathrm{X}$-axis and $\mathrm{Y}$-axis of the projection plane. Furthermore, the targets are also useful to permit the scaling of the model through one known measurement.

Then we could pick any distance in the model to find out the exact real measure.

At least, we could take advantage of the orthophoto of front elevations and put them in the appropriate scales of reduction, for reproductions of work and for display panels for any exhibitions, where the aspect ratio is definitely essential.

The work was carried out thanks to the availability and logistical support of the Carabinieri for the Protection of Cultural Heritage which has hosted in the headquarters of Trastevere where the urns were in custody during the restoration.

The Etruscan Museum of Perugia, where now is the urn found (along with all the others), plans to make an exhibition video which goes to explain the myth of Oenomaus and morphological characteristics of the urn.

Therefore, following the definition of the 3D model, one of the works carried out has been precisely to recreate, in Cinema 4D software, a movie set of lighting and shooting video.

The digital urn was illuminated with effect's lights and sliding to highlight the chiaroscuro with sharp shadows, and dark background. In this way, the figures seem to emerge from urn so marked by darkness, as after the archaeological find (Fig. 12).
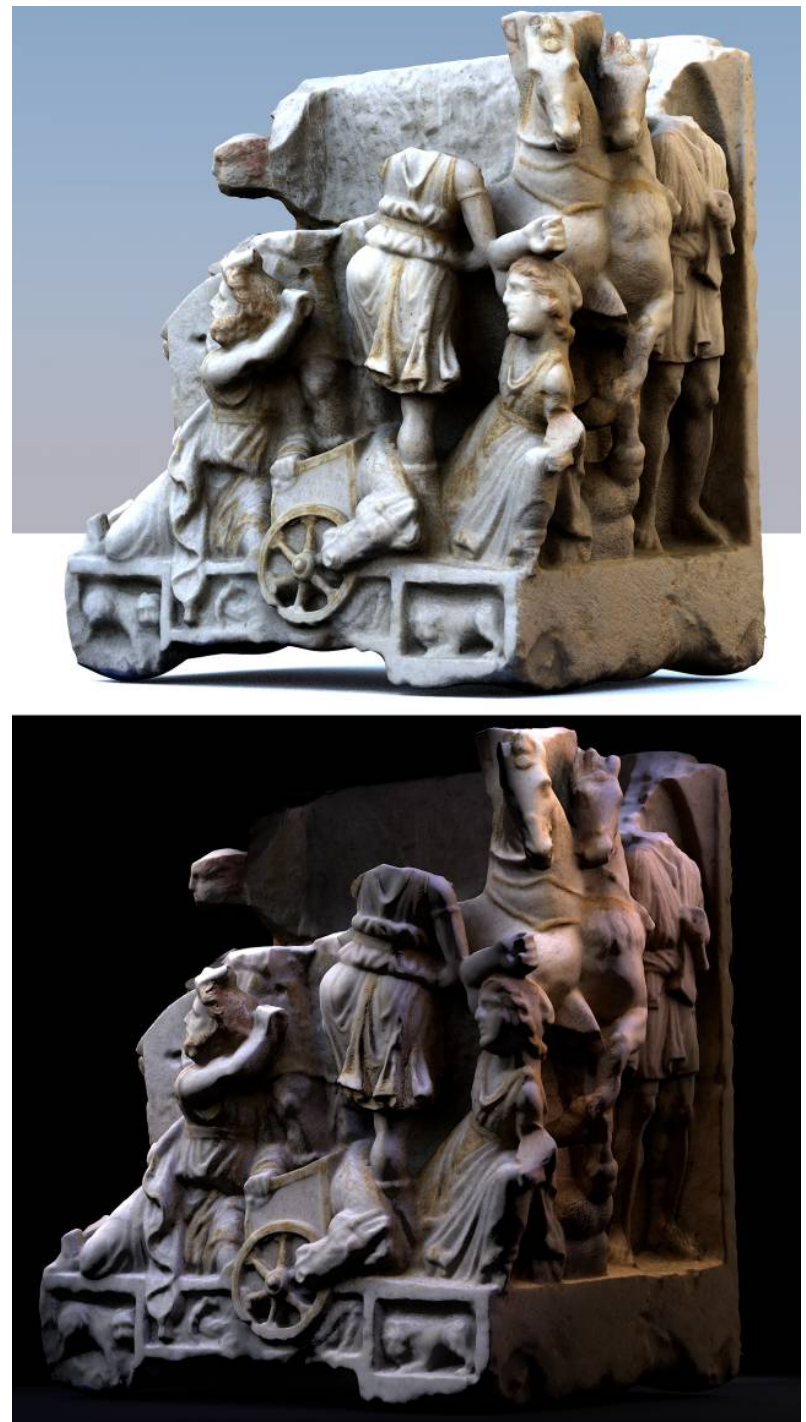

Figure 12: The 3D model obj exported and imported into Cinema 4D, then illuminated by sunlight (with its shadows) or subject to set of lights at night to give greater emphasis to the digital urn.

An emphasis of forms allows to better represent the myth and make the story more dramaturgy appealing.

\section{Conclusion}

The modern instruments for surveying are always a source of renewable solutions and new open to future developments. We must grapple with these instruments, know them, understand them and know what might be the application fields. 
In this example the use of the laser scanner was totally unnecessary given the considerable problems of the shadow zones, and it was unthinkable to join together 138 shots by laser scanner.

Instead, the photo modelling has led to a result of considerable precision and to the possibility of more various uses.

Exploiting the 3D mesh model to create photorealistic video of the urn is certainly both a way to divulge the importance of a priceless artistic heritage, and a way, at the same time, to preserve the original object. All the operations of setting, lighting, recovery are totally on the digital platform and performed on a copy almost perfect of the real artistic work (Fig. 13) (Debevec 2004). (Debevec et al. 2002).

We believe that the proposed case study, is an excellent example of what today would be the relationship with art and the artistic and cultural heritage that abounds in Italy: protection and preservation but at the same time divulging and research.

The experiments and research until now personally conducted showed some characteristics of the photographic modeling. Currently it is quite complicated to be able to get accurate meshed model in all its parts for large architectures: in the case of the church of Santa Maria di Loreto, the 3D model obtained is certainly very useful but has large gaps in precision ornaments, capitals or moldings; they require more detailed elaboration with detailed photographs.

However, PhotoScan and photographic modeling, produce excellent results for items that are not constructed geometrically. Statues, bas-reliefs, archaeological excavations and ruins in general are certainly very noticeable with the tools presented in this paper.

\section{Acknowledgements}

A special thanks to Marshal of the Carabinieri Sebastian Antoci, which allowed the execution of the survey. The photogrammetric survey was performed by Margherita Caputo and Luisa Bogliolo. Thanks to Roberto de Paolis to take the pictures on the site. The 3D model, animations and graphics processing were performed by Daniel Calisi.
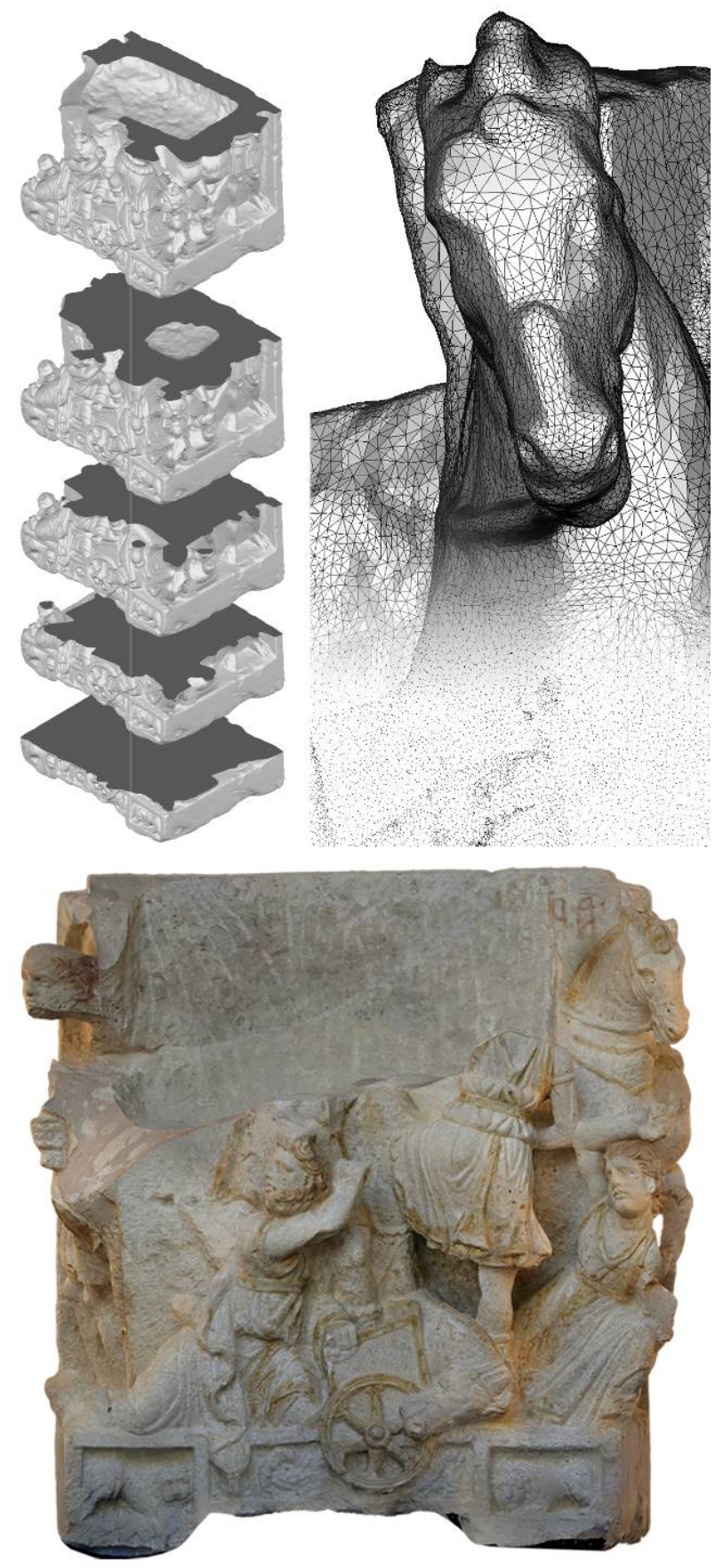

Figure 13: Composition of some of the processing on the 3D model. Axonometric view with some horizontal sections of relevance. Render of the mesh network and overlap with the point cloud. Down, orthophotos of the main front, rendered as an orthogonal projection in high resolution.

\section{References}

AA.VV., 2014. Catalogo della mostra "La memoria ritrovata. Tesori recuperati dall'Arma dei Carabinieri". Roma, Palazzo del Quirinale, 23 gennaio - 16 marzo 2014, a cura di Louis Godart, CIVITA.

CALISI, D., and AA. VV., 2014. Schede di rilievi in "Italian Survey, National and International Portfolio". ISBN 978-88548-7508-1

CALISI, D. and CIANCI, M.G., 2014. Storia e contemporaneità nella ricostruzione della Chiesa di Santa Maria di Loreto, In: XXXVI Convegno Internazionale dei Docenti della Rappresentazione "Italian Survey and International Experience" - UID 2014. ISBN 978-88492-2915-8 
DEBEVEC, P., 2004. Postproduction Re-Illumination of Live Action Using Time-Multiplexed Lighting. In: ICT Technical Report. DOI: 10.1145/1186415.1186470

DEBEVEC, P., WENGER, A., TCHOU, C., GARDNER, A., WAESE, J. and HAWKINS, T., 2002. A Lighting Reproduction Approach to Live-Action Compositing. SIGGRAPH 2002 (August). DOI: 10.1145/566570.566614

DE LUCA, L., 2011. La Fotomodellazione Architettonica. Palermo, Italy. Dario Flaccovio Editore, 2011. ISBN:978-88579-0070-4

DE LUCA, L., BUSARAYAT, C., STEFANI, C., VERON, P. and FLORENZANO, M., 2011. A semantic-based platform for the digital analysis of the architectural heritage, Computers \& Graphics. Volume 35, Issue 2, April 2011, Elsevier. Pages 227-241. DOI: 10.1016/j.cag.2010.11.009

PIERROT-DESEILLIGNY, M., DE LUCA, L. and REMONDINO, F., 2011. Automated ImageBased Procedures for Accurate Artifacts 3D Modeling and Orthoimage, Proceedings of XXIIIrd International CIPA Symposium, Prague, Czech Republic, September 12 - 16. DOI: http://dx.doi.org/10.14311/gi.6.36 